\title{
Ephaptic crosstalk in painful diabetic neuropathy: an electrodiagnostic study
}

\author{
Ahmad Asmedi ${ }^{1,2 *}$, Samekto Wibowo ${ }^{2}$, Lucas Meliala ${ }^{2}$ \\ ${ }^{1}$ Doctoral Student, Doctoral Programme, Faculty of Medicine Universitas Gadjah Mada, \\ ${ }^{2}$ Department of Neurology, Dr. Sardjito General Hospital/Faculty of Medicine, Universitas Gadja \\ Mada, Yogyakarta
}

DOI: http://dx.doi.org/10.19106/JMedSci005002201806

\begin{abstract}
Painful Diabetic Neuropathy (PDN) is a common complication of diabetes mellitus (DM) which significantly causes pain and distress in patients. Release of factors from degenerating fibers activating adjacent fibers to produce ephaptic crosstalk have been proposed as one of the pain mechanism in PDN. Here we aim to detect ephaptic crosstalk between small fibers and large fibers in PDN subjects by comparing the electrodiagnostic result of patients with PDN and patients without PDN.

This study used cohort prospective design. Patients with type 2 DM or impaired glucose tolerance (IGT) without PDN from several health facilities in Yogyakarta were followed for 12 months for the occurrence of PDN. Demographic, clinical, laboratory and electrodiagnostic data from all patients were collected and analyzed.

One hundred and forty-one subjects (58 men, 83 women) with an average age of 51 years (range, 40-61 years), were enrolled in this study. After 48 weeks of observation, 12 subjects were found to have PDN. The differences of distal latency between PDN and non-PDN group were significant when measured in median sensory nerve $(4.47 \mathrm{~ms}$ \pm 2.43 versus $3.39 \mathrm{~ms} \pm 1.79, p=0.002)$, tibial motor nerve $(6.96 \mathrm{~ms} \pm 3.07$ versus $5.90 \mathrm{~ms} \pm 2.17, p=0.041)$, and sural sensory nerve $(6.02 \mathrm{~ms} \pm 3.56$ versus 3.55 $\mathrm{ms} \pm 2.90, p<0.001)$. Among all parameters measured in this study, the $\mathrm{H}$-reflex had higher abnormality persentage compared to other electrodiagnostic variable $(\mathrm{H}$ latency $=$ $30 \%, \mathrm{H}$ amplitude $=71 \%, \mathrm{H} / \mathrm{M}$ Ratio $=88 \%$, and $\mathrm{H}-\mathrm{M} \mathrm{IPL}=15 \%$ ).

Our result shows that small fiber neuropathy in PDN can be detected by electrodiagnostic study which measures large fibers function. This indicates that ephaptic crosstalk between small fiber and large fiber happens in PDN.
\end{abstract}

Keyword : Painful diabetic neuropathy - NCS - ephaptic- Diabetes Mellitus

\section{INTRODUCTION}

Painful diabetic neuropathy (PDN) and post herpetic neuralgia $(\mathrm{PHN})$ are the most frequent painful neuropathies. ${ }^{1}$ Painful diabetic neuropathy significantly causes pain and distress in patients with diabetes mellitus (DM). Approximately 30\% of patients with

\footnotetext{
* corresponding author: aasmedi@yahoo.com
}

DM develop PDN. ${ }^{2}$ The pain is typically worse at night and characterized by typical neuropathic pain descriptors (burning, tingling, aching, dysesthesia). Sometimes sensory loss can also be found. Over 50\% of patients report significant problem in performing activities of daily living, including mobility, work, sleep, recreation and social activities. ${ }^{3}$ This condition can lead to serious 
psychological problem. Sleep deprivation following prolonged periods of intense pain can lead to apathy towards life in general, and/ or self-imposed social isolation. Some may also experience reduced memory retention, mood swings and suicidal tendencies. ${ }^{2}$

Diabetic neuropathy is characterized by progressive distal neurodegeneration. This condition adds an additional layer of complexity in identifying pathogenic mechanisms for neuropathic pain in diabetic patients. This nerve degeneration has been proposed as a mechanism responsible for pain generation in neuropathy. ${ }^{4}$ Assessment of the most distal regions of sensory axons have shown the possibility that mechanisms by which nerve degeneration may cause pain include ectopic activity by destabilized degenerating fibers and the release of factors from degenerating fibers activating adjacent fibers to produce ephaptic crosstalk. ${ }^{4}$

Ephaptic (electrical) crosstalk has been long proposed as a mechanism of neuropathic pain. It is a form of fiber-to fiber interaction found in neuromas and demyelination plaques in nerves and spinal roots. ${ }^{5}$ the normal anatomy and physiology of pain; second, the pathophysiology of damaged sensory neurons; and third, the diagnosis and treatment of patients with neuropathic pain. The book begins with a discussion of neural mechanisms relevant to pain perception along with a brief review of neuropathic pain. This is followed by separate chapters on hyperalgesia following cutaneous injury; the importance of peripheral processes in the etiology of neuropathic and radiculopathic pain; and mechanisms by which sympathetic efferent fibers contribute to the occurrence of pain. Subsequent chapters cover the diagnosis and treatment of reflex sympathetic dystrophy; pain in generalized neuropathies; surgical treatment of pain; clinical features and management of postherpetic neuralgia; diagnosis of cancer pain syndromes; and drugs in the management of chronic pain. Nerve conduction study is commonly used to evaluate large myelinated sensory and motor nerve fibers, but is ineffective in diagnosing small fiber neuropathies. ${ }^{6}$ In case of PDN however, ephaptic crosstalk will result in activation of large fibers near the demyelinated $\mathrm{C}$ fibers. This phenomenon should be able to be detected by electrodiagnostic (EDx) study. The aim of this study was to detect ephaptic crosstalk between small fibers and large fibers in PDN subjects by comparing the electrodiagnostic result of patients with PDN and patients without PDN.

\section{MATERIALS AND METHODS}

\section{Subjects}

This was an observational study using cohort prospective design. The inception cohort was diabetes patients free from PDN (ID pain score less than 2), followed by a 12-months disease follow-up. The subjects of this study were diabetic patients admitted to Diabetes Outpatient Clinic in Dr. Sardjito General Hospital, Yogyakarta, members of Indonesian Diabetic Association at PKU Hospital Yogyakarta, staffs of Health Science Academy of Aisiyah, Yogyakarta and prediabetic patients involving in the research conducted in Department of Clinical Pathology, Dr. Sardjito General Hospital, Yogyakarta. The protocol of study was approved by the Medical and Health Research Ethics Committees of Faculty of Medicine, Gadjah Mada University.

\section{Protocol of study}

On the appointed day, subjects were gathered to be selected. Explanations 
concerning the background, objective, benefit of the study was provided. Subject who meet the inclusion and exclusion criteria and were willing to involve in the study were provided an informed consent to be signed. The inclusion criteria were men and women aged 20 to 60 years old, with type $2 \mathrm{DM}$ or impaired glucose tolerance (IGT), as defined by American Diabetes Association (ADA) criteria. The following were reasons for exclusion: 1) anatomical deformities on extremities that would interfere with electrodiagnostic study protocol; 2) pregnancy or lactation; 3) a documented history of lumbosacral surgery that would interfere with electrodiagnostic study protocol; 4) other diseases known to be associated with pain, especially chronic pain in the feet that the investigator believed would interfere with the assessment of pain associated with diabetic neuropathy, like cancer pain, lumbosacral abnormality or other entrapment neuropathy; 5) any acute or underlying serious illness that are likely to interfere with completion of the trial.

Clinical and electrodiagnostic examinations were performed in all patients. Baseline assessments, consisted of ID pain, neuropathy symptom score (NSS), diabetic neuropathy symptom (DNS), review of nerve conduction study of upper and lower extremity, and soleus H-reflex study, were done at week 1. Nerve conduction study and $\mathrm{H}$ reflex were conducted using an MEB-2300K ENMG machine (Nihon Kohden, Tokyo, Japan). The evaluation and recording of PDN occurrence were carried out every week up to 12 months by self-assessment which was monitored by the doctors.

\section{Statistical analysis}

Data were presented as mean \pm standard deviation (SD) or percentage or range.
Student t test was used to compare between PDN and non PDN groups. A p value $<0.05$ was considered as significant.

\section{RESULTS}

One hundred and forty-one subjects (58 men, 83 women) with an average age of 51 years (range: 40-61 years), were enrolled in this study. The hyperglycemia state were diabetic in $65 \%$ and IGT in $35 \%$ of the subjects. The mean glucose level was $116 \mathrm{mg} /$ dL (range: $78-200 \mathrm{mg} / \mathrm{dL}$ ) for fasting, 170 $\mathrm{mg} / \mathrm{dl}$ for $2 \mathrm{~h}$ post prandial (range: $90-250$ $\mathrm{mg} / \mathrm{dL}$ ). The mean value of HbA1c was $6.9 \%$ (range: 4 - $7 \%$ ). Screening by NSS and DNS scores at admission found that 57 subjects (40.4\%) were diagnosed as neuropathy (DN) according to NSS, while 68 (48.2\%) were diagnosed as neuropathies according to DNS. There were no subjects diagnosed as PDN. However, upon completion of 48 weeks of observation, 12 subjects were found to have PDN.

The electrodiagnostic study showed that there were prolonged distal latencies in PDN group, while there was no abnormality found in non-PDN group (TABLE 1). The differences of distal latency between PDN and non-PDN group were significant when measured in median sensory nerve $(4.47 \pm 2.43 \mathrm{~ms}$ versus $3.39 \pm 1.79 \mathrm{~ms}, \mathrm{p}=0.002)$, tibial motor nerve $(6.96 \pm 3.07 \mathrm{~ms}$ versus $5.90 \pm 2.17 \mathrm{~ms}, \mathrm{p}=$ $0.041)$, and sural sensory nerve $(6.02 \pm 3.56$ $\mathrm{ms}$ versus $3.55 \pm 2.90 \mathrm{~ms}, \mathrm{p}<0.001)$. There was no significant difference in median motor nerve $(4.90 \pm 0.84 \mathrm{~ms}$ versus $4.44 \pm 1.46 \mathrm{~ms}$, $\mathrm{p}=0.119)$.

In the measurement of H-reflex, the H-latency prolonged in both groups, but significantly longer in PDN group (38.90 \pm $5.94 \mathrm{~ms}$ versus $34.82 \pm 6.32 \mathrm{~ms}, \mathrm{p}=0.004)$. The M-latency was also significantly longer 
$(\mathrm{p}=0.003)$ in PDN group $(9.37 \pm 3.01 \mathrm{~ms})$ compared to non-PDN group $(7.51 \pm 2.74$ $\mathrm{ms})$. Nerve conduction velocity in PDN group decreased significantly compared to the non-PDN group $(p<0.05)$. The median nerve conduction velocity in PDN group was 44.69 $\pm 10.78 \mathrm{~m} / \mathrm{s}$, and $51.51 \pm 9.08 \mathrm{~m} / \mathrm{s}$ in non-PDN group $(\mathrm{p}=0.001)$. The tibial nerve conduction velocity was $33.52 \pm 14.86 \mathrm{~m} / \mathrm{s}$ in PDN group, and $41.45 \pm 9.64 \mathrm{~m} / \mathrm{s}$ in non-PDN group ( $\mathrm{p}=$ $0.001)$.

There were significantly smaller distal amplitudes in PDN group compared to nonPDN group in median motor nerve $(3.45 \pm 1.82$ $\mathrm{mV}$ versus $8.37 \pm 6.27 \mathrm{mV}, \mathrm{p}<0.001)$, median sensory nerve $(6.02 \pm 10.32 \mu \mathrm{V}$ versus 14.95 $\pm 15.95 \mu \mathrm{V}, \mathrm{p}=0.008)$, tibial motor nerve (4.47 $\pm 3.45 \mathrm{mVversus} 7.22 \pm 4.47 \mathrm{mV}, \mathrm{p}=0.004)$, and sural nerve $(4.37 \pm 4.16 \mu \mathrm{V}$ versus $13.89 \pm$
$14.09 \mu \mathrm{V}, \mathrm{p}=0.001)$. There was also significant difference $(p=0.001)$ between the H-reflex amplitude in PDN group and non-PDN group. The H-reflex amplitude was abnormal in PDN group $(0.29 \pm 0.42 \mathrm{mV})$ while normal in nonPDN group $(1.32 \pm 1.52 \mathrm{mV})$.

The PDN group also had significantly longer H-M Inter Peak Latency (32.21 \pm 6.56 $\mathrm{ms})$ compared to non-PDN group $(27.53 \pm 5.87$ $\mathrm{ms})(\mathrm{p}=0.0020$. The H/M Ratio decreased for both groups, but significantly lower ( $\mathrm{p}=$ $0.016)$ in PDN $(11.23 \% \pm 17.896)$ compared to non-PDN $(25.53 \% \pm 27.97)$. Among all parameters measured in this study, the H-reflex had higher abnormality persentage compared to other electrodiagnostic variable $(\mathrm{H}$ latency $=30 \%, \mathrm{H}$ amplitude $=71 \%, \mathrm{H} / \mathrm{M}$ Ratio $=88 \%$, and H-M IPL $=15 \%)($ Table 2$)$.

TABLE 1. The analysis of electrodiagnostic parameters value towards PDN status.

\begin{tabular}{llrrrr}
\hline \multicolumn{1}{c}{ Parameter } & \multicolumn{1}{c}{ Variable } & \multicolumn{1}{c}{$\begin{array}{c}\text { Non-PDN } \\
( \pm \text { SD })\end{array}$} & \multicolumn{1}{c}{$\begin{array}{c}\text { PDN } \\
( \pm \text { SD })\end{array}$} & \multicolumn{1}{c}{ p } & CI 95\% \\
\hline Distal Latency & Median motor $(\mathrm{ms})$ & $4.44(1.46)$ & $4.90(0.84)$ & 0.119 & $-0.12-1.08$ \\
& Median sensory $(\mathrm{ms})$ & $3.39(1.79)$ & $4.74(2.43)$ & 0.002 & $0.52-2.19$ \\
& Tibial motor $(\mathrm{ms})$ & $5.90(2.17)$ & $6.96(3.07)$ & 0.041 & $0.04-2.09$ \\
& Sural sensory $(\mathrm{ms})$ & $3.55(2.90)$ & $6.02(3.56)$ & $<0.001$ & $1.15-3.79$ \\
Nerve Conduction & Median $(\mathrm{m} / \mathrm{s})$ & $51.51(9.08)$ & $44.69(10.78)$ & 0.001 & $-10.91--2.72$ \\
Velocity & Tibial $(\mathrm{m} / \mathrm{s})$ & $41.45(9.64)$ & $33.52(14.86)$ & 0.001 & $-12.68-3.17$ \\
Distal & Median motor $(\mathrm{mV})$ & $8.37(6.27)$ & $3.45(1.82)$ & $<0.001$ & $-7.40--2.40$ \\
Amplitude & Median sensory $(\mu \mathrm{V})$ & $14.95(15.95)$ & $6.02(10.32)$ & 0.008 & $-15.50--2.30$ \\
& Tibial motor $(\mathrm{mV})$ & $7.22(4.47)$ & $4.47(3.45)$ & 0.004 & $-4.60--0.87$ \\
Amplitude & Sural $(\mu \mathrm{V})$ & $13.89(14.09)$ & $4.37(4.16)$ & 0.001 & $-15.15-0.89$ \\
Latency & H-reflex $(\mathrm{mV})$ & $1.32(1.52)$ & $0.29(0.42)$ & 0.001 & $-1.65--0.42$ \\
M-latency & H-reflex $(\mathrm{ms})$ & $34.82(6.32)$ & $38.90(5.94)$ & 0.004 & $01.35-6.81$ \\
H-M IPL & H-reflex $(\mathrm{ms})$ & $7.51(2.74)$ & $9.37(3.01)$ & 0.003 & $0.64-3.08$ \\
H/M Ratio & H-reflex $(\mathrm{ms})$ & $27.53(5.87)$ & $32.21(6.56)$ & 0.002 & $1.60-6.84$ \\
\hline
\end{tabular}

This table shows that all electrodiagnostic parameters differ significantly between the group with and without PDN $(p<0.05)$, except for distal latency of median nerve. PDN= painful diabethic neuropathy. 
TABLE 2. Abnormality percentage of electrodiagnostic variable

\begin{tabular}{|c|c|c|c|c|c|}
\hline \multirow{2}{*}{ Variable } & \multirow{2}{*}{ Parameter } & \multicolumn{2}{|c|}{ Result } & \multirow{2}{*}{$\mathbf{p}$} & \multirow{2}{*}{$\begin{array}{c}\text { Abnormality } \\
\% \\
\end{array}$} \\
\hline & & Non-PDN & PDN & & \\
\hline \multirow{3}{*}{ Median (motor) } & Amplitude & normal & decrease & sig. & 35 \\
\hline & D. Latency & normal & prolonged & ns. & - \\
\hline & $\mathrm{NCV}$ & normal & slowed & sig. & 14 \\
\hline \multirow{3}{*}{ Tibial (motor) } & Amplitude & normal & normal & sig. & 0.6 \\
\hline & D. Latency & normal & prolonged & sig. & 16 \\
\hline & $\mathrm{NCV}$ & normal & slowed & sig. & 20 \\
\hline \multirow{2}{*}{ Median (sensory) } & Amplitude & normal & decrease & sig. & 50 \\
\hline & Latency & normal & prolonged & sig. & 35 \\
\hline \multirow{2}{*}{ Sural (sensory) } & Amplitude & normal & normal & sig. & 0 \\
\hline & Latency & normal & & sig. & 50 \\
\hline \multirow{4}{*}{ H-reflex } & H Latency & prolonged & prolonged & sig. & 30 \\
\hline & H Amplitude & normal & decrease & sig. & 71 \\
\hline & $\mathrm{H} / \mathrm{M}$ ratio & decrease & decrease & sig. & 88 \\
\hline & H-M IPL & normal & prolonged & sig. & 15 \\
\hline
\end{tabular}

This table reveals that, generally, electrodiagnostic parameters in non PDN group are still normal, while almost all parameters in PDN group are abnormal. The highest percentage of abnormality was found in the decrease of $\mathrm{H}$ reflex amplitude (88\%). sig= significant ; $n s=$ not significant.

\section{DISCUSSION}

The study population in this research was patients with abnormality in blood glucose level (DM or IGT). The clinical neurological complication focused in this study was state of being neuropathy with and without PDN. After observation for almost 12 months, we found around $40 \%$ of the subjects with neuropathy and $12 \%$ with PDN. Electrodiagnostic study was performed in all subjects in the initial recruitment of this study. Motoric and sensoric nerve conduction study and the $\mathrm{H}$ reflex study were conducted. According to Skljarevski $\&$ Malik, ${ }^{7}$ attributes of nerve conduction are reliable, reproducible, and objective primary outcome measures in trials evaluating pharmaceutical treatment of diabetic peripheral neuropathy. The principal factors affecting nerve conduction velocity (NCV) are: the integrity and degree of myelination of the largest diameter fibers; the mean axonal cross-sectional diameter; the representative internodal distance, and the distribution of nodal ion channels. ${ }^{7}$ Our study found that almost all EDx variables in non PDN subjects were normal. This result indicated that the large myelin fibers investigated were intact.

In healthy peripheral nerves, individual myelinated axons form discrete and highly isolated conduction channels. ${ }^{5}$ a stable electrical (ephaptic ${ }^{8}$ Each sensory neuron functions as an independent conduction channel until it reaches the synapse. In injured nerve, however, disruption of glial ensheathment allows adjacent denuded axons to make contact, permitting both electrical (ephaptic) and chemical (via a diffusible substance) cross-excitation. ${ }^{9}$ This phenomenon can be seen in PDN subjects. Prolonged latency and decreased amplitudo were found in almost all parameters of EDx in PDN subjects, except in the latency of median motor nerve. Orstavik ${ }^{10}$ has previously reported about altered properties of afferent C-fibres in a chronic painful condition. This phenomenon 
can happen in chronic hyperglycemic subjects. Previous researches have shown that ephaptic crosstalk can be the source of the pathologic pain. ${ }^{11}$ Acute transection of a neuron has been shown to be able to short-circuit neighboring axons in a nerve so that the current from the cut end of one fiber can excite the others. ${ }^{5}$,a stable electrical (ephaptic ${ }^{8}$ The same mechanism happen in PDN. Electrical impulse running through demyelinated axons in PDN can trigger demyelinated axons near it to also fire. Ephaptic crosstalk between fibers mediating light touch $(\mathrm{A} \beta)$ and those involved in the generation of pain $(\mathrm{C}$ and $\mathrm{A} \delta$ ) may account for the generation of pain by light tactile stimulation. ${ }^{12,13}$

Collateral sprouting from primary afferent fibers, which induces ephaptic or physical crosstalk between different types of fibers, have been proposed to be involved in reorganization mechanisms of spinal neuronal circuits for pain transmission. ${ }^{13}$ The damage to the nerves can cause regeneration of nerve sprouts, called neuromas, at the stump. The sprouting of the new nerves in all directions causes damage to healthy nerves nearby and expands the sensitized area. Hyper excitability in the neuroma generates ectopic impulses that affect neighboring intact afferents and the cell bodies of the dorsal root ganglion. ${ }^{14}$ Lysophosphatidic acid (LPA), which is released at the dorsal root, demyelinates the $\mathrm{A} \delta$ - and $\mathrm{A} \beta$-fibers on the dorsal root through the LPA 1 receptor, followed by physical (or ephaptic) crosstalk between the C-fiber and $\mathrm{A} \delta$-fiber, and between the $\mathrm{A} \delta$-fiber and $\mathrm{A} \beta$ fiber. ${ }^{13}$

Decreased conduction velocity and increased activity dependent slowing are possible pathological features of a small fiber neuropathy like PDN. ${ }^{10,15}$ Our research shows that the processes can also be detected by EDx study which assess large fibers. This fact supports the idea that ephaptic crosstalk between small fibers with large fibers really happens in PDN. After ephaptic transmission, the action potentials of the two cells were conducted at almost the same velocity along the axons. The conduction velocity of the action potential was reduced from $0.30 \pm 0.11 \mathrm{~cm} / \mathrm{s}$ to $0.15 \pm 0.05 \mathrm{~cm} / \mathrm{s}$ by ephaptic transmission of the action potential. "container-title":"Plant and Cell Physiology","page":"575-579","vo lume":"31","issue":"5","source":"pcp. oxfordjournals.org","abstract":"When two separated Chara internodal cells were kept in contact over a length of $14 \mathrm{~mm}$ or more in moist air, an action potential of one cell could be transmitted to the other cell in about $40 \%$ of cases (ephaptic transmission

\section{CONCLUSION}

In conclusion, our result shows that small fiber neuropathy in PDN can be detected by EDx study which measures large fibers function. This indicates that ephaptic crosstalk between small fiber and large fiber happens in PDN. To our knowledge this is the first report of altered properties of afferent $\mathrm{C}$ fibers in a chronic painful condition captured by electrodiagnostic study which actually measures the large fibers function.

\section{ACKNOWLEDGEMENTS}

We would like to thank dr. Djoko Dwijono for helping in statistical analysis, dr. Rusdy Ghazali Malueka, PhD. and dr. Melania Testudinaria for helping in writing the manuscript.

\section{REFERENCES}

1. Baron R. Mechanisms of disease: neuropathic pain--a clinical perspective. Nat Clin Pract Neurol 2006; 2(2):95-106. https://doi.org/10.1038/ncpneuro0113 
2. Kirby M. Painful diabetic neuropathy current understanding and management for the primary care team. Br J Diabetes Vasc Dis 2003; 3:138-44.

https://doi.org/10.1177/14746514030030021 001

3. Kota SK, Meher LK, Jammula S, Kota SK, Modi KD. Diabetic peripheral neuropathyrecent trends and future perspectives in management. Int J Clin Cases Investig 2012; 4(2):44-59.

4. Zecuatl TM, Calcutt NA. Biology and Pathophysiology of Painful Diabetic Neuropathy. In: Lawson E, Misha M (eds). Painful Diabetic Polyneuropathy: A Comprehensive Guide for Clinicians. New York: Springer Science+Business Media, 2013.

5. Fields HL. Pain Syndromes in Neurology: Butterworths International Medical Reviews. Butterworth-Heinemann, 1990.

6. Misra UK, Kalita J, Nair PP. Diagnostic approach to peripheral neuropathy. Ann Indian Acad Neurol 2008; 11(2):89-97. https://doi.org/10.4103/0972-2327.41875

7. Skljarevski V, Malik RA. Clinical diagnosis of diabetic neuropathy. in: Diabetic neuropathy .clinical management. New Jersey: Humana Press, 2007.

https://doi.org/10.1007/978-1-59745-311$0 \_16$

https://doi.org/10.1007/978-1-59745-3110_1

8. Seltzer Z, Devor M. Ephaptic transmission in chronically damaged peripheral nerves. Neurology 1979; 29(7):1061-4. https://doi.org/10.1212/WNL.29.7.1061
9. Taylor BK. Pathophysiologic mechanisms of neuropathic pain. Curr Pain Headache Rep 2001; 5(2):151-61. https://doi.org/10.1007/s11916-001-0083-1

10. Ørstavik K, Namer B, Schmidt R, Schmelz $\mathrm{M}$, Hilliges $\mathrm{M}$, Weidner $\mathrm{C}$ et al. Abnormal function of C-fibers in patients with diabetic neuropathy. J Neurosci 2006; 26(44):1128794.

h t t p s : //d o i.org/10.1523/ JNEUROSCI.2659-06.2006

11. Hooshmand H. Chronic Pain: Reflex Sympathetic Dystrophy, Prevention, and Management. CRC Press, 1993.

12. Love S, Coakham HB. Trigeminal neuralgia: pathology and pathogenesis. Brain 2001; 124(Pt 12):2347-60. https://doi.org/10.1093/brain/124.12.2347

13. UedaH.Peripheral mechanisms of neuropathic pain - involvement of lysophosphatidic acid receptor-mediated demyelination. Mol Pain 2008; 4:11. https://doi.org/10.1186/1744-8069-4-11

14. AslamA, Singh J, Rajbhandari S. Pathogenesis of painful diabetic neuropathy. Pain Res Treat 2014; 2014:412041. https://doi.org/10.1155/2014/412041

15. Tabata T. Ephaptic transmission and conduction velocity of an action potential in Chara internodal cells placed in parallel and in contact with one another. Plant Cell Physiol 1990; 31: 575-579. 